Article

\title{
A Facile Synthetic Route to Amphiphilic Poly(Meta-Phenylene Ethynylene) and Poly(Meta-Phenylene Ethynylene)- Block-Polyisocyanide Using a Single Catalyst
}

\author{
Chonglong $\mathrm{Li}^{1,2}{ }^{10}$, Xunhui Xu ${ }^{1}$, Lei $\mathrm{Xu}^{1}$ and $\mathrm{Na}$ Liu ${ }^{1, *}$ \\ 1 Department of Polymer Science and Engineering, School of Chemistry and Chemical Engineering, \\ and Anhui Key Laboratory of Advanced Functional Materials and Devices, Hefei University of Technology, \\ Hefei 230009, China; lililong0@126.com (C.L.); xuxunhui@mail.hfut.edu.cn (X.X.); \\ 18856036326@163.com (L.X.) \\ 2 School of Chemistry and Chemical Engineering, North Minzu University, Yinchuan 750021, China \\ * Correspondence: liuna@hfut.edu.cn; Tel.: +86-0551-6290-2264
}

Received: 21 June 2018; Accepted: 19 August 2018; Published: 23 August 2018

\begin{abstract}
An optically active, amphiphilic meta-phenylene ethynylene ( $m$-PE) bearing a chiral amide pendant was designed and synthesized. Living polymerization of $m$-PE using alkyne-Pd(II) as the initiator afforded well-defined poly (meta-phenylene ethynylene) ( $m$-PPE). These $m$-PPEs were found to have a stable helical conformation in THF, 1,4-dioxane, and $\mathrm{CH}_{3} \mathrm{CN}$ and showed split Cotton effects over the range of $245-400 \mathrm{~nm}$. The positive first Cotton effect was observed at a wavelength of approximately $308 \mathrm{~nm}$, and the negative second Cotton effect was observed at a wavelength of approximately $289 \mathrm{~nm}$. The $m$-PPEs exhibited helical conformational changes in different mixed solvents and showed effective solvent-dependent helix inversion in $\mathrm{CHCl}_{3} / \mathrm{THF}$ solutions. The sign of the Cotton effect of $m$-PPE was inverted at $25^{\circ} \mathrm{C}$ by varying the mixing ratio of THF and $\mathrm{CHCl}_{3}$. Finally, amphiphilic poly (meta-phenylene ethynylene)-block-polyisocyanide containing hydrophilic PPE and hydrophobic PPI segments were facilely prepared using Pd(II)-terminated $m$-PPE as the macroinitiator. This block copolymer can self-assemble into well-defined spherical nanostructures in a selective $\mathrm{THF} / \mathrm{CH}_{3} \mathrm{OH}$ solution. This efficient polymerization will open up enormous opportunities for the preparation of functional amphiphilic block copolymers in a wide variety of fields.
\end{abstract}

Keywords: helical polymers; helix inversion; poly(meta-phenylene ethynylene); poly(meta-phenylene ethynylene)-block-polyisocyanide

\section{Introduction}

Helical polymers, such as chiral packing materials for separating enantiomers in chromatography [1,2], asymmetric catalysis [3-6], and chiral selectors $[7,8]$ have attracted considerable research attention during the past few decades in the fields of polymer chemistry and materials science. To date, many optically active helical polymers have been synthesized by direct polymerization of monomers with the required functional groups. Moore and his collaborators found that $m$-PPEs was able to fold into a compact helical conformation in polar solvents, such as acetonitrile [9-11], and were capable of binding small molecules, such as (-)- $\alpha$-pinene [12]. Therefore, $m$-PPEs have potential for use as chiral and biological materials $[13,14]$.

Currently, $m$-PPEs is one of the most popular structural motifs for foldamers and can assume either a left-handed or right-handed helical conformation, with the helix controlled by either thermodynamics or kinetics. Many $m$-PPEs exist as synergistic dynamic helical foldamers during excess single-handed 
helix formation; these are chain molecules that have a specific conformational state in solution, and their structures are stabilized through a series of intra- and/or intermolecular noncovalent bonding interactions [15].

The helical reversal states that separate left- and right-handed helical segments are unfavorable in terms of energy. Therefore, helical polymers require energy to convert between left- and right-handed helical conformations. The dynamic helical polymers have a very low helix inversion barrier. Using externally supplied energy, the polymer can overcome the small energy barrier of helical inversion, and it is easy to undergo a helix-helix transition from one helical conformation to another. Therefore, helix inversion can be induced by the application of external stimuli $[16,17]$, such as changing the temperature [18-21], light [22,23], metal ions [24-26], $\mathrm{pH}$ [27,28], and solvent composition [29-31]. Some studies have reported the results of helix-helix inversion of PPE without the help of extraneous molecules [32].

In this study, amphiphilic $m$-PE bearing a chiral amide pendant was designed and synthesized. Polymerization of $m$-PE afforded a well-defined $m$-PPE, which was achieved via the catalyst-transfer polycondensation mechanism based on $\mathrm{Pd}(\mathrm{II})$-catalyzed Sonogashira coupling reactions [33]. The helical structure of $m$-PPE was rigid and stable, and it had a dynamic folded conformation. Meanwhile, it was found that $m$-PPE formed a preferred-handed helix in the presence of solvents such as $\mathrm{CH}_{3} \mathrm{CN}$ and THF and that helix-helix inversion occurred in $\mathrm{THF} / \mathrm{CHCl}_{3}$ solutions.

PPEs and their block copolymers have been widely used in explosives detection [34] and molecular wire applications $[35,36]$. Since polyisocyanide can easily form into a rigid helical conformation, it has been connected to PPE to provide better block copolymers. It is known that the synthesis of poly(meta-phenylene ethynylene)-block-polyisocyanide has been achieved in previous works using Pd(II)-terminated $m$-PPE as the macroinitiator. These block copolymers can self-assemble into well-defined spherical nanostructures in selective solvents. In the future, amphiphilic block copolymers will provide new materials with interesting self-assembly and optical properties. Thus, the development of novel well-defined block copolymers with stable helical conformation is of great interest.

\section{Experimental}

\subsection{Chemicals and Reagents}

All solvents were obtained from Sinopharm. Co. Ltd. (Beijing, China). and were distilled under reduced pressure prior to use. All chemicals were purchased from Aladdin (Shanghai, China), Sinopharm (Beijing, China), and Sigma-Aldrich Chemical Co. Ltd. (St. Louis, MO, USA) and were used as received without further purification unless noted otherwise. Phenylene ethynylene monomer 1 was prepared according to the procedures reported by Ramakrishnan [37] and Yashima [38]. The Pd(II) initiator and poly-1 $\mathbf{1}_{\mathrm{m}}$ were prepared according to procedures previously reported by our group [39-41]. All structures were confirmed by ${ }^{1} \mathrm{H}$ NMR spectra, ${ }^{13} \mathrm{C}$ NMR, and FT-IR.

\subsection{Instrumentation and Characterization}

${ }^{1} \mathrm{H}$ and ${ }^{13} \mathrm{C}$ NMR spectra were recorded using a $600 \mathrm{MHz}$ Bruker (Bruker, Fremont, CA, USA). FT-NMR spectrometer (600 MHz, or $150 \mathrm{MHz}$, respectively). Size exclusion chromatography (SEC) was performed with a Waters 1515 pump and Waters 2414 differential refractive index (RI) detector (Waters, Milford, MA, USA) (set at $40^{\circ} \mathrm{C}$ ) using a series of two linear TSK gel GMHHR-H columns. Molecular weight $\left(M_{\mathrm{n}}\right)$ and polydispersity $\left(M_{\mathrm{w}} / M_{\mathrm{n}}\right)$ data were reported relative to those of the polystyrene standards. Tetrahydrofuran (THF) was used as the eluent at a flow rate of $0.8 \mathrm{~mL} / \mathrm{min}$. FT-IR spectra were recorded with a Perkin-Elmer Spectrum (Thermo Nicolet, Waltham, MA, USA) BX FT-IR system using $\mathrm{KBr}$ pellets at $25^{\circ} \mathrm{C}$. Circular dichroism (CD) and UV-vis absorption spectra were obtained using a JASCO J1500 spectropolarimeter (JASCO, Tokyo, Japan) and UNIC 4802 UV/VIS double beam spectrophotometer (Unico, Dayton, NJ, USA), respectively. Atomic force microscopy (AFM) images 
were acquired at room temperature in the tapping mode with a Digital Instruments Dimension 3100 Scanning Probe Microscope (Bruker, Karlsruhe, Germany). Transmission electron microscopy (TEM) was performed on a JEM-2100F operating at an accelerating voltage of $200 \mathrm{kV}$ (JEOL, Tokyo, Japan).

\subsection{Representative Polymerization Procedure for PPE (Poly-1 $\mathbf{1}_{25}$ )}

A $10 \mathrm{~mL}$ oven-dried flask was charged with triphenylphosphine $\left(\mathrm{PPh}_{3}\right)(3.41 \mathrm{mg}, 13.0 \mu \mathrm{mol})$ and a stirring bar. A solution of bis(triethylphosphine)-((4-methoxyphenyl)ethynyl) palladium(II) chloride $(1.33 \mathrm{mg}, 2.62 \mu \mathrm{mol})$ in dry THF $(0.3 \mathrm{~mL})$ was then added under dry nitrogen. After the reaction flask was stirred at $30{ }^{\circ} \mathrm{C}$ for $3 \mathrm{~h}$, copper iodide (CuI) $(2.48 \mathrm{mg}, 13.0 \mu \mathrm{mol})$, a solution of monomer $1(31.16 \mathrm{mg}, 65.6 \mu \mathrm{mol})$ in dry THF $(0.3 \mathrm{~mL})$, and $\mathrm{Et}_{3} \mathrm{~N}(0.2 \mathrm{~mL})$ were added under a dry nitrogen atmosphere. The reaction flask was then immersed in an oil bath and stirred at $55^{\circ} \mathrm{C}$ for $10 \mathrm{~h}$. The progress of the polymerization was monitored by SEC until the molecular weight of the yielded poly- $\mathbf{1}_{25}$ ceased to increase. After cooling to room temperature, the polymerization solution was precipitated in a large amount of $n$-hexane, collected by centrifugation, and dried in vacuum at room temperature overnight to afford the desired poly- $\mathbf{1}_{25}(15.94 \mathrm{mg}, 70 \%)$. SEC: $M_{\mathrm{n}}=6.38 \mathrm{kDa}$, $M_{\mathrm{w}} / M_{\mathrm{n}}=1.17 .{ }^{1} \mathrm{H}$ NMR $\left(600 \mathrm{MHz}, \mathrm{CDCl}_{3}, 25{ }^{\circ} \mathrm{C}\right) \delta: 8.05-7.90(\mathrm{br}, 2 \mathrm{H}), 7.82-7.72(\mathrm{br}, 1 \mathrm{H}), 7.54-7.45$ (br, 1H), 3.80-3.50 (br, 12H), 3.46-3.41 (br, 2H), 3.32-3.29 (br, 1H), 3.29-3.24 (br, 3H), 1.24-1.19 (br, 3H).

\subsection{Representative Copolymerization Procedure for PPE-b-PPI (poly $\left.\left(\mathbf{1}_{25}-b-\mathbf{2}_{60}\right)\right)$}

Monomer 2 (24.16 mg, $84 \mu \mathrm{mol}$ ) was added to a solution of freshly generated Pd(II)-terminated PPE macroinitiator (poly- $\mathbf{1}_{25}, M_{\mathrm{n}}=6.38 \mathrm{kDa}, M_{\mathrm{w}} / M_{\mathrm{n}}=1.17$ ), and the reaction mixture was stirred at $55^{\circ} \mathrm{C}$ for $12 \mathrm{~h}([2] 0=0.1 \mathrm{M},[2] 0 /[\mathrm{Pd}] 0=60 / 1)$. When the molecular weight ceased to increase according to SEC, the solution was quenched by precipitation into a large amount of $\mathrm{CH}_{3} \mathrm{OH}$. The precipitated solid was collected by filtration and washed with cold THF and $\mathrm{CH}_{3} \mathrm{OH}$ to afford the desired block copolymer poly $\left(\mathbf{1}_{25}-b-\mathbf{2}_{60}\right)(34.54 \mathrm{mg}, 79 \%$ yield over the two steps) as a yellow solid. SEC: $M_{\mathrm{n}}=21.5 \mathrm{kDa}, M_{\mathrm{w}} / M_{\mathrm{n}}=1.20 .{ }^{1} \mathrm{H}$ NMR $\left(600 \mathrm{MHz}, \mathrm{CDCl}_{3}, 25^{\circ} \mathrm{C}\right): \delta 7.09-8.02(\mathrm{br}, 6 \mathrm{H}, \mathrm{ArH}$ of PPE and PPI segment), 5.51-6.05 (br, 2H, ArH of PPI segment), 4.42-3.27 (br, 20H, $\mathrm{OCH}_{2}$ of PPE and $\mathrm{CO}_{2} \mathrm{CH}_{2}$ of PPI segment of PPE segment), 1.97-0.87 (br, 22H, $\mathrm{CH}_{3}$, alkyl chains of PPI segments).

\section{Results}

\subsection{Homopolymerization of m-PPE and Its Chiroptical Properties}

\subsubsection{Synthesis and Polymerization of Optically Active $m$-Phenylene Ethynylenes}

The optically active monomer $\mathbf{1}$ was synthesized according to literatures reported by Ramakrishnan and Yashima, as outlined in Scheme S1.

We used the $\mathrm{Pd}(\mathrm{II})$ initiator to prepare amphiphilic conjugated polymer $m$-PPE. As shown in Scheme 1, polymerization of monomer 1 was carried out in THF at $55^{\circ} \mathrm{C}$ using the $\operatorname{Pd}(\mathrm{II})$ complex and triethylamine in the presence of $\mathrm{PPh}_{3}$ and CuI under a dry nitrogen atmosphere $([1] 0 /[\mathrm{Pd}] 0=25$, $[\mathrm{PPh} 3] 0 /[1] 0=0.2,[1] 0=0.12 \mathrm{M})$. The reaction mixtures were stirred in THF at $55^{\circ} \mathrm{C}$ for $10 \mathrm{~h}$. When the molecular weight of the polymer ceased to increase, the reaction was quenched with $n$-hexane and separated by centrifugation. We successfully synthesized the desired homopolymer poly- $\mathbf{1}_{\mathrm{m}}$ (the subscript indicates the initial feed ratio of the monomer to initiator, the same notation is used below) as confirmed by SEC analysis. The $M_{\mathrm{n}}$ and $M_{\mathrm{w}} / M_{\mathrm{n}}$ of synthetic poly-1 $\mathbf{1}_{25}$ were determined up to $6.38 \mathrm{kDa}$ and 1.17, respectively, by SEC analysis with polystyrene standards (Table 1). ${ }^{1} \mathrm{H}$ NMR spectra of the isolated poly- $\mathbf{1}_{25}$ were measured in $\mathrm{CDCl}_{3}$ at room temperature (Figure S19, Supplementary Materials). 

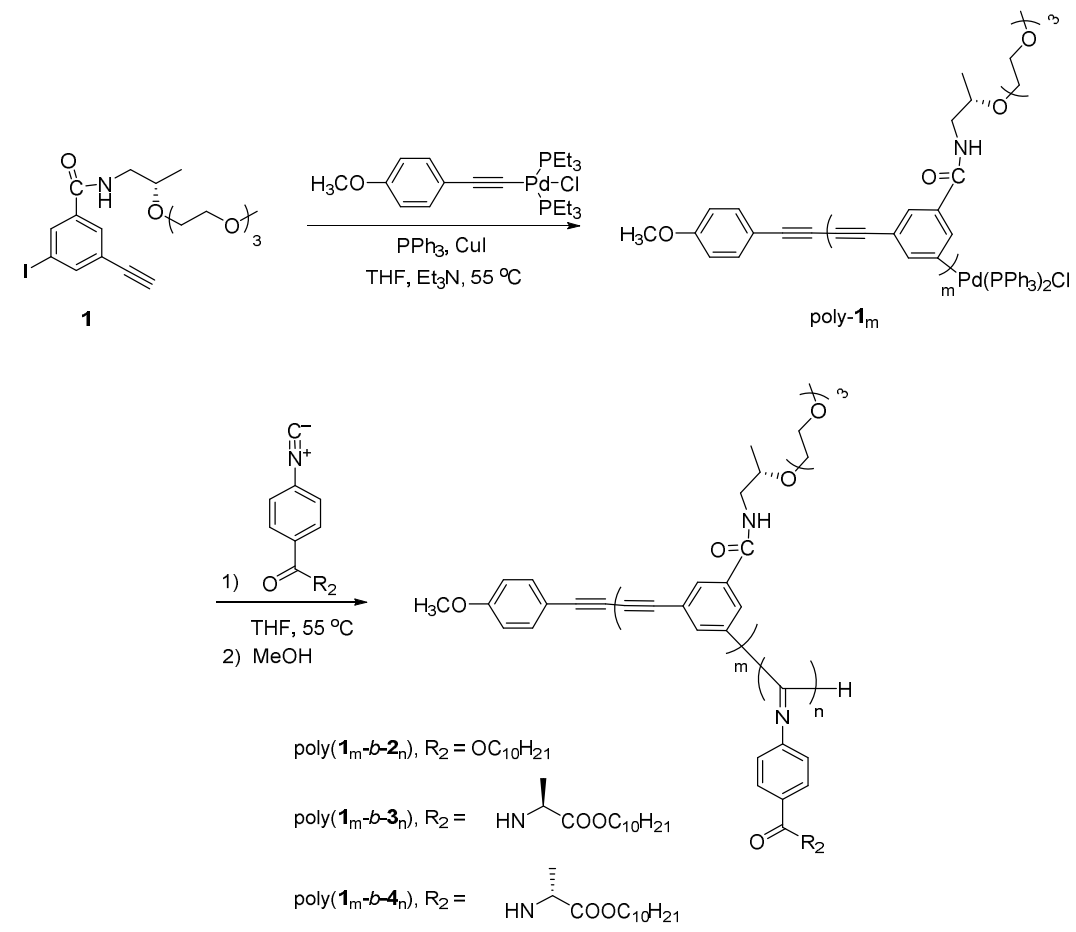

Scheme 1. Synthesis of the Poly-1 $\mathbf{1}_{\mathrm{m}}$ Homopolymer and PPE- $b$-PPI block copolymer.

Table 1. Results for the polymerization of monomer 1 using the $\mathrm{Pd}(\mathrm{II})$ Initiator in $\mathrm{THF}$ at $55^{\circ} \mathrm{C}^{a}$.

\begin{tabular}{cccccc}
\hline Run & Polymer $^{\boldsymbol{b}}$ & {$[\mathbf{1}] \mathbf{0} /\left[\mathbf{P d} \mathbf{0}^{c}\right.$} & $\boldsymbol{M}_{\mathbf{n}} \mathbf{( k D a}^{\boldsymbol{d}}$ & $\boldsymbol{M}_{\mathbf{w}} \boldsymbol{M}_{\mathbf{n}}{ }^{\boldsymbol{d}}$ & Yield $^{\boldsymbol{e}} \mathbf{( \% )}$ \\
\hline 1 & poly-1 $_{10}$ & 10 & 2.51 & 1.20 & 67 \\
2 & poly-1 $_{15}$ & 15 & 3.74 & 1.19 & 67 \\
3 & poly-1 $_{20}$ & 20 & 5.07 & 1.21 & 70 \\
4 & poly-1 $_{25}$ & 25 & 6.38 & 1.17 & 70 \\
5 & poly-1 $_{30}$ & 30 & 7.42 & 1.18 & 73 \\
6 & poly-1 $_{35}$ & 35 & 8.57 & 1.21 & 78 \\
\hline
\end{tabular}

${ }^{a}$ The polymers were prepared according to the Scheme 1 in main text. ${ }^{b}$ The footnote indicates the initial feed ratio of monomer 1 to the $\operatorname{Pd}(\mathrm{II})$ initiator. ${ }^{c}$ The initial feed ratio of monomer 1 to the $\operatorname{Pd}(\mathrm{II})$ initiator. ${ }^{d} M_{\mathrm{n}}$ and $M_{\mathrm{W}} / M_{\mathrm{n}}$ values were measured by SEC using polystyrene standards. ${ }^{e}$ The isolated yield.

A series of polymerizations of monomer 1 using the $\operatorname{Pd}(\mathrm{II})$ initiator were carried out with different initial feeding ratios of monomer $\mathbf{1}$ to the initiator in THF at $55{ }^{\circ} \mathrm{C}$ (Figure 1a). As expected, all of the isolated polymers were isolated at high yields $(>65 \%)$, and the molecular weight of the polymer gradually increased with the increase of the initial feed ratio of $[1]_{0} /[\mathrm{Pd}]_{0}$. Moreover, as shown in Figure $1 \mathrm{~b}$, the $M_{\mathrm{n}} \mathrm{s}$ values of the isolated poly-1 $\mathbf{1}_{\mathrm{m}}$ were linearly correlated to the initial feed ratio of $[1]_{0} /[\mathrm{Pd}]_{0}$. All of the polymer dispersity values were narrowly distributed with $M_{\mathrm{w}} / M_{\mathrm{n}}<1.30$ (Table 1). The structure of the isolated poly-1 $\mathbf{m}_{\mathrm{m}}$ was further verified by ${ }^{1} \mathrm{H}$ NMR analysis. 

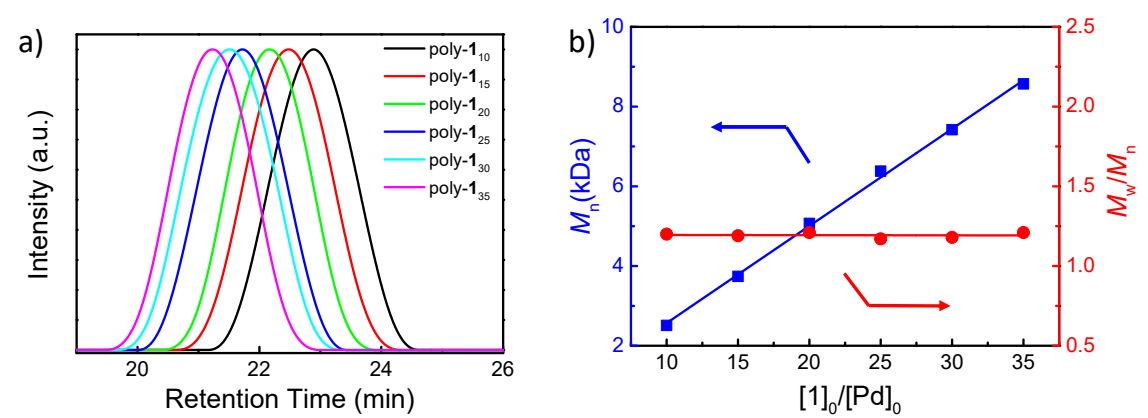

Figure 1. (a) Size exclusion chromatography (SEC) chromatograms of poly-1 $\mathbf{1}_{\mathrm{m}}$ prepared via polymerization of monomer 1 using the $\mathrm{Pd}(\mathrm{II})$ catalyst in THF with different initial feed ratios of monomer to catalyst. (b) Plots of the $M_{\mathrm{n}}$ and $M_{\mathrm{w}} / M_{\mathrm{n}}$ values of poly-1 $\mathbf{1}_{\mathrm{m}}$ with the initial feed ratio of monomer $\mathbf{1}$ to the $\operatorname{Pd}(\mathrm{II})$ initiator. $M_{\mathrm{n}}$ and $M_{\mathrm{w}} / M_{\mathrm{n}}$ were determined by SEC with the polystyrene standard (SEC conditions: eluent $=\mathrm{THF}$, temperature $=40^{\circ} \mathrm{C}$ ).

\subsubsection{Chiroptical Properties in Dilute Solution}

Ester-bound $m$-PPEs folded into helical conformations in acetonitrile and adopted random-coil conformation in $\mathrm{CHCl}_{3}$ [12]. In the UV-vis spectra of Ester-bound $m$-PPEs, the ratio of the UV maximum absorbances at 303 and $289 \mathrm{~nm}$ showed that the foldamers had almost the same relative intensity and were in a randomly oriented conformation in a mixture of the cisoid and transoid states in $\mathrm{CHCl}_{3}[9,12]$. Oligomers with low values of $A_{303} / A_{289}$ had a high degree of folding [9]. In acetonitrile, on the other hand, a decrease of $A_{303} / A_{289}$ in the UV spectra was observed [42,43]. Yashima and coworkers previously reported that poly(meta-phenylene ethynylene)s bearing L-alanine-derived oligo(ethylene glycol) side chains ((S)-PPEa) had a preferred-handed helical conformation induced by the covalent bonding of chiral alanine pendants, even in $\mathrm{CHCl}_{3}$ [38]. In $\mathrm{CHCl}_{3}$, the helical conformation of (S)-PPEa is likely to be stabilized by intramolecular hydrogen bonds between nonadjacent amide pendants [38].

To compare the folding properties of poly-1 $\mathbf{1}_{25}$, the chiroptical properties were investigated in different solvents at $25{ }^{\circ} \mathrm{C}$ by $\mathrm{CD}$ (Figure 2). It was observed that poly-1 $\mathbf{1}_{25}$ underwent a solventdependent conformational transition from an approximately random-coil conformation in $\mathrm{CHCl}_{3}$ to a helical structure in acetonitrile. Poly-1 $\mathbf{1}_{25}$ showed similar split Cotton effects in THF, 1,4-dioxane, and $\mathrm{H}_{2} \mathrm{O}$ over the range of $245-400 \mathrm{~nm}$, i.e., the positive first Cotton effect occurred at a wavelength of approximately $308 \mathrm{~nm}$ and the negative second Cotton effect occurred at a wavelength of approximately $289 \mathrm{~nm}$. However, poly-1 $\mathbf{1}_{25}$ showed a negligible $\mathrm{CD}$ signal in $\mathrm{CHCl}_{3}$, indicating that the intramolecular hydrogen bonds in the poly-1 $\mathbf{1}_{25}$ chains might interfere with the chiral induction of the main chain with the chiral amide pendants and formed the helical structure of poly- $\mathbf{1}_{25}$ with lower regularity. The CD spectra of poly- $\mathbf{1}_{25}$ showed a positive first Cotton effect at $308 \mathrm{~nm}$ at $25^{\circ} \mathrm{C}$ in $\mathrm{CH}_{3} \mathrm{CN}$, which was a poor solvent for the main chain, but a good solvent for the sidechain. In THF and 1,4-dioxane, the interior stress in the polymer was relaxed and the chiral amide pendant was able to be efficiently induced to afford stronger $\mathrm{CD}$ absorptions of poly- $\mathbf{1}_{25}$. 


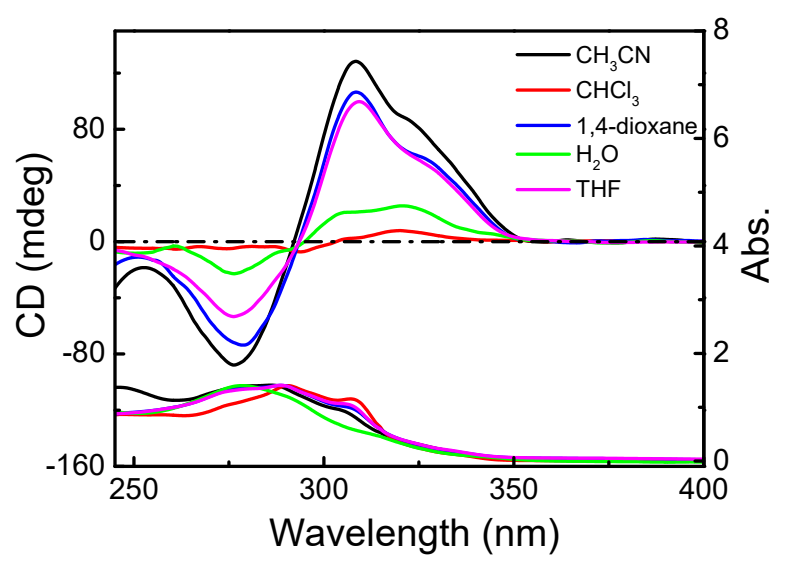

Figure 2. CD and UV spectra of poly- $\mathbf{1}_{25}$ measured in different solvents at $25^{\circ} \mathrm{C}(\mathrm{c}=0.04 \mathrm{mg} / \mathrm{mL})$.

The CD and UV-vis spectra of poly- $\mathbf{1}_{25}$ were measured to characterize the chiroptical properties of optically active $m$-PPE. We have found an interesting phenomenon that when $0.15 \mathrm{~mL}$ of a $\mathrm{CHCl}_{3}$ solution of poly-1 $\mathbf{1}_{25}(1.0 \mathrm{mg} / \mathrm{mL})$ was added to $2.85 \mathrm{~mL}$ of THF, a completely different response was observed in THF $/ \mathrm{CHCl}_{3}$ solutions with a $5 \%$ volume of $\mathrm{CHCl}_{3}$. As shown in Figure $3 \mathrm{c}$, poly-1 $\mathbf{1}_{25}$ had a negative $C D$ signal at approximately $308 \mathrm{~nm}$ and a positive $C D$ signal at a wavelength of approximately $289 \mathrm{~nm}$ in the THF/ $\mathrm{CHCl}_{3}$ solvents. The Cotton effect of poly- $\mathbf{1}_{25}$ in $\mathrm{THF} / \mathrm{CHCl}_{3}$ was opposite in sign to that in pure THF at the same concentration, indicating that the polymer assumed helical conformations with reversed senses in the mixture solvents. Upon the addition of $0.15 \mathrm{~mL}$ of a $\mathrm{CHCl}_{3}$ solution containing poly- $\mathbf{1}_{25}$ at various concentrations to 1,4-dioxane, we found that poly-1 $\mathbf{1}_{25}$ assumed a helical conformation with reversed senses in 1,4-dioxane $/ \mathrm{CHCl}_{3}$ solutions containing $5 \%$ of $\mathrm{CHCl}_{3}$ by volume compared to pure 1,4-dioxane (Figure 3d). However, upon addition of $0.15 \mathrm{~mL}$ of a $\mathrm{CHCl}_{3}$ solution containing poly-1 $\mathbf{1}_{25}$ at various concentrations to $\mathrm{CH}_{3} \mathrm{CN}$, we found that poly-1 $\mathbf{1}_{25}$ assumed the same helical conformations as that those in the pure $\mathrm{CH}_{3} \mathrm{CN}$ solution (Figure 3a).
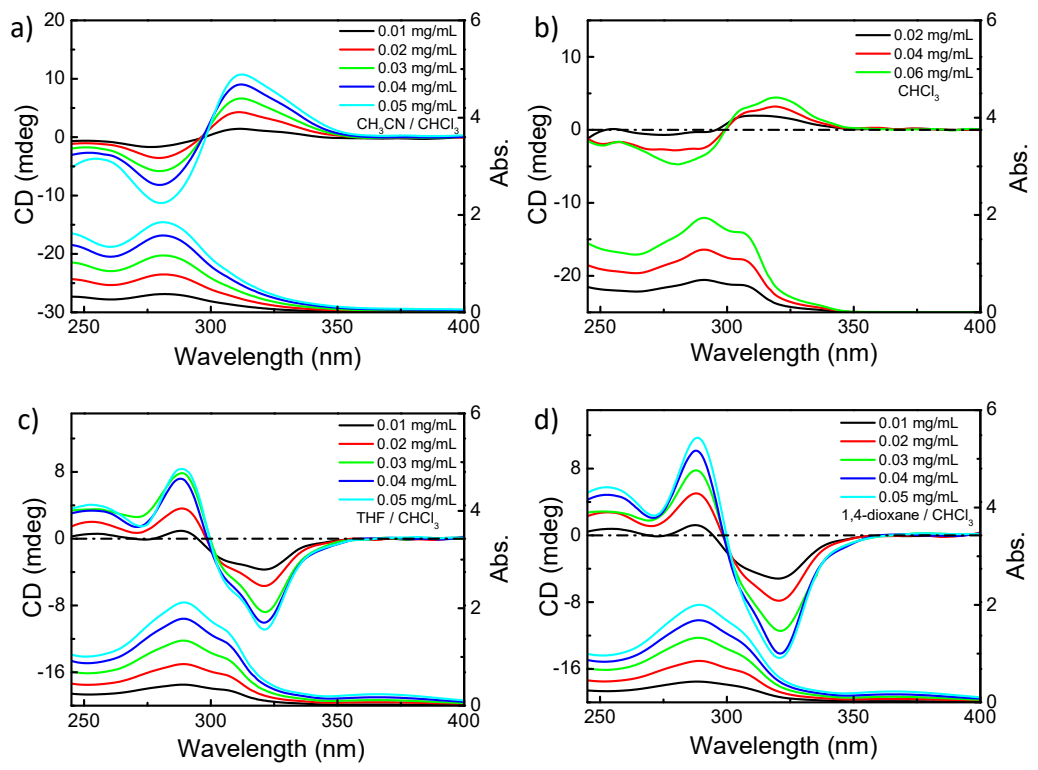

Figure 3. $\mathrm{CD}$ and $\mathrm{UV}$-vis spectra of poly- $\mathbf{1}_{25}$ in mixed solvents containing $5 \%$ of $\mathrm{CHCl}_{3}$ by volume at $25^{\circ} \mathrm{C}$ in various concentrations. (a) $\mathrm{CH}_{3} \mathrm{CN}$ and $\mathrm{CHCl}_{3}$. (b) $\mathrm{CHCl}_{3}$. (c) $\mathrm{THF}$ and $\mathrm{CHCl}_{3}$. (d) 1,4-dioxane and $\mathrm{CHCl}_{3}$. 
To compare the helix inversion properties of poly- $\mathbf{1}_{25}$, the chiroptical properties were studied at different ratios of THF to $\mathrm{CHCl}_{3}$ at $25^{\circ} \mathrm{C}$ by CD spectroscopy UV-vis spectra (Figure 4). Therefore, it was expected that the helical inversion occurred according to the change of the solvent composition between $\mathrm{CHCl}_{3}$ and THF. Adding $0.09 \mathrm{~mL}$ of a $\mathrm{CHCl}_{3}$ solution $(1.0 \mathrm{mg} / \mathrm{mL})$ containing poly- $\mathbf{1}_{25}$ to different ratios of THF and $\mathrm{CHCl}_{3}$ at a concentration of $0.03 \mathrm{~g} / \mathrm{L}$, we further investigated the effect of the solvents on the poly- $\mathbf{1}_{25} \mathrm{CD}$ and UV-vis spectral patterns. The polymer exhibited a positive first CD signal and an intense UV-vis absorption peak at $308 \mathrm{~nm}$ in $\mathrm{THF} / \mathrm{CHCl}_{3}$ solutions with a $10 \%$ THF fraction (Figure 4). As the percentage of THF in $\mathrm{CHCl}_{3}$ increased from $10 \%$ to $30 \%$, the positive first Cotton effect of poly-1 $\mathbf{1}_{25}$ increased steadily and the CD signals were still positive at $308 \mathrm{~nm}$. When THF reached $40 \%$, the first CD signal intensity suddenly decreased. Upon further increasing the THF amount to $50 \%$, the portion of the CD signals at $322 \mathrm{~nm}$ inverted to the opposite signs and had a negative value. The CD spectra intensity at $322 \mathrm{~nm}$ in a $70 \%$ THF solution showed the largest negative value, which was almost identical to that in a $97 \%$ THF solution. The positive first CD signal at $308 \mathrm{~nm}$ gradually transformed into a negative $\mathrm{CD}$ signal with the increase of the THF volume in the $\mathrm{THF} / \mathrm{CHCl}_{3}$ mixtures.

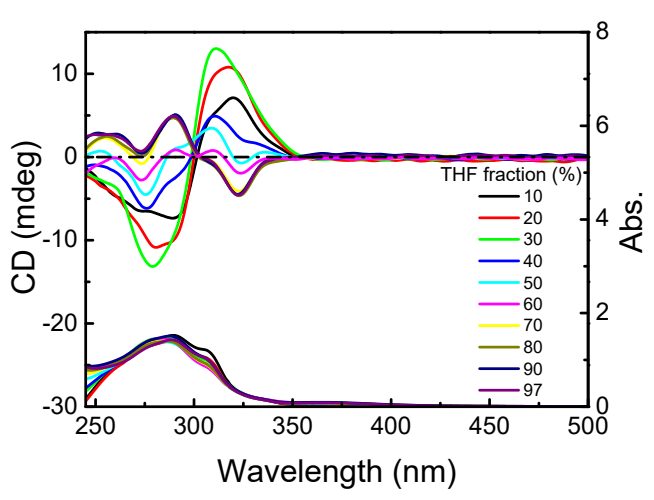

Figure 4. $\mathrm{CD}$ and $\mathrm{UV}$-vis spectra of poly- $\mathbf{1}_{25}$ measured in $\mathrm{THF} / \mathrm{CHCl}_{3}$ solutions with different THF fractions at the concentration of $0.03 \mathrm{~g} / \mathrm{L}$.

It was observed from these results that the poly-1 $\mathbf{1}_{25}$ changed from a helix structure with a predominantly single-handed helix to a helix structure with the opposite screw sense; this change did not occur via the random coil structure, but rather through a direct helix-helix transformation with the change of the THF $/ \mathrm{CHCl}_{3}$ composition. The helical transition from one predominant handedness to another spanning a wide composition range might be caused by the competitive interactions between the molecules of the two solvents of THF and $\mathrm{CHCl}_{3}$ with the amide chains.

It is considered that the conformations of the polymers at different ratios of THF to $\mathrm{CHCl}_{3}$ are energetically favorable to assume one-handed helices with positive or negative CD signals. Such transitions are thought to result from the entropy difference between the left- and right-handed helices produced by changes in the structure of the main chains and side chains, or changes in the solvation, or changes intra- and intermolecular hydrogen bond interactions; however, the exact mechanism of this transition is still unclear.

\subsection{One-Pot Synthesis of a PPE-b-PPI Block Copolymer and Chiroptical Properties}

According to Scheme 1, polymerization of monomer 1 was carried out using the $\mathrm{Pd}(\mathrm{II})$ complex according to the procedure described above $([\mathbf{1}] 0 /[\mathrm{Pd}] 0=25,[\mathrm{PPh} 3] 0 /[1] 0=0.2,[1] 0=0.12 \mathrm{M})$. When polymerization of monomer 1 was completed as indicated by SEC, a THF solution of cyanide monomer $3([3] 0=0.15 \mathrm{M},[3] 0 /[\mathrm{Pd}] 0=30)$ was added to the reaction system, and the mixture was stirred at $55^{\circ} \mathrm{C}$ for $10 \mathrm{~h}$. When the molecular weight of the polymer ceased to increase, the reaction was quenched by $\mathrm{CH} 3 \mathrm{OH}$. The residue was concentrated, dissolved with a small amount of THF, and poured into 
$\mathrm{CH} 3 \mathrm{OH}$ to precipitate the solid. The yield of poly $\left(\mathbf{1}_{25}-b-\mathbf{3}_{30}\right)$ was $70 \%$ in two steps. The SEC of the obtained poly $\left(\mathbf{1}_{25}-b-\mathbf{3}_{30}\right)$ was located in the shorter retention-time region compared to that of poly- $\mathbf{1}_{25}$. The $M_{\mathrm{n}}$ of $\operatorname{poly}\left(\mathbf{1}_{25}-b-\mathbf{3}_{30}\right)$ was estimated to be $13.8 \mathrm{kDa}\left(M_{\mathrm{w}} / M_{\mathrm{n}}=1.10\right)$, which was larger than that of poly-1 $\mathbf{1}_{25}\left(M_{\mathrm{n}}=6.38 \mathrm{kDa}, M_{\mathrm{w}} / M_{\mathrm{n}}=1.17\right)$. To verify the activity of $\operatorname{Pd}(\mathrm{II})$-terminated poly $\left(\mathbf{1}_{25}-b-\mathbf{3}_{30}\right)$, freshly $\mathrm{Pd}(\mathrm{II})$-terminated poly $\left(\mathbf{1}_{25}-b-\mathbf{3}_{30}\right)$ was prepared and monomer $\mathbf{3}$ in THF was added into the system. The $M_{\mathrm{n}}$ of the resulting poly $\left(\mathbf{1}_{25}-b-\mathbf{3}_{60}\right)$ was determined to be $25.3 \mathrm{kDa}$, larger than that of poly $\left(\mathbf{1}_{25}-b-3_{30}\right)\left(M_{\mathrm{n}}=13.8 \mathrm{kDa}, M_{\mathrm{w}} / M_{\mathrm{n}}=1.10\right)$ (Figure 5a). Taking advantage of the living nature of the block copolymerization, a series of block copolymers was obtained using $\mathrm{Pd}(\mathrm{II})$-terminated poly-1 $1_{25}\left(M_{\mathrm{n}}=6.38 \mathrm{kDa}, M_{\mathrm{w}} / M_{\mathrm{n}}=1.17\right)$ as the macroinitiator. All of the block copolymers were isolated at high yields, and the results of the one-pot block copolymerization are summarized in Table 2. The plots of the $M_{\mathrm{n}}$ and $M_{\mathrm{w}} / M_{\mathrm{n}}$ values of poly $\left(\mathbf{1}_{\mathrm{m}}-b-\mathbf{3}_{\mathrm{n}}\right) \mathrm{s}$ with the initial feed ratios of monomer 3 to the macroinitiator, $\mathrm{Pd}(\mathrm{II})$-terminated poly- $\mathbf{1}_{25}$, are summarized in Figure $5 \mathrm{~b}$.

Table 2. Results for the One-Pot Synthesis of PPE- $b$-PPI Block Copolymers ${ }^{a}$.

\begin{tabular}{|c|c|c|c|c|}
\hline Run & Block Polymer ${ }^{b}$ & $M_{\mathrm{n}}(\mathrm{kDa})^{c}$ & $M w / M_{n}^{c}$ & Yield $^{d}(\%)$ \\
\hline 1 & $\operatorname{poly}\left(\mathbf{1}_{25}-b-\mathbf{2}_{15}\right)$ & 9.08 & 1.15 & 73 \\
\hline 2 & poly $\left(\mathbf{1}_{25}-b-\mathbf{2}_{50}\right)$ & 17.80 & 1.21 & 78 \\
\hline 3 & poly $\left(\mathbf{1}_{25}-b-\mathbf{2}_{100}\right)$ & 31.75 & 1.17 & 81 \\
\hline 4 & $\operatorname{poly}\left(\mathbf{1}_{25}-b-\mathbf{3}_{20}\right)$ & 11.64 & 1.14 & 78 \\
\hline 5 & poly $\left(\mathbf{1}_{25}-b-\mathbf{3}_{60}\right)$ & 25.33 & 1.09 & 81 \\
\hline 6 & poly $\left(\mathbf{1}_{25}-b-\mathbf{4}_{20}\right)$ & 11.16 & 1.16 & 77 \\
\hline 7 & poly $\left(\mathbf{1}_{25}-b-\mathbf{4}_{30}\right)$ & 14.15 & 1.15 & 81 \\
\hline 8 & poly $\left(\mathbf{1}_{25}-b-\mathbf{4}_{60}\right)$ & 22.86 & 1.21 & 80 \\
\hline
\end{tabular}

${ }^{a}$ The block copolymers were synthesized according to Scheme 1 by first preparing the macroinitiator, followed by the addition of monomer 2,3 , or 4 as denoted. ${ }^{b}$ The footnotes indicate the initial feed ratios of monomer to initiator $([\mathrm{M}] 0 /[\mathrm{Pd}] 0) .{ }^{c}$ The $\mathrm{Mn}$ and $\mathrm{Mw} / \mathrm{Mn}$ values were determined by SEC and reported as their polystyrene equivalents. ${ }^{d}$ Isolated yield over the two steps.
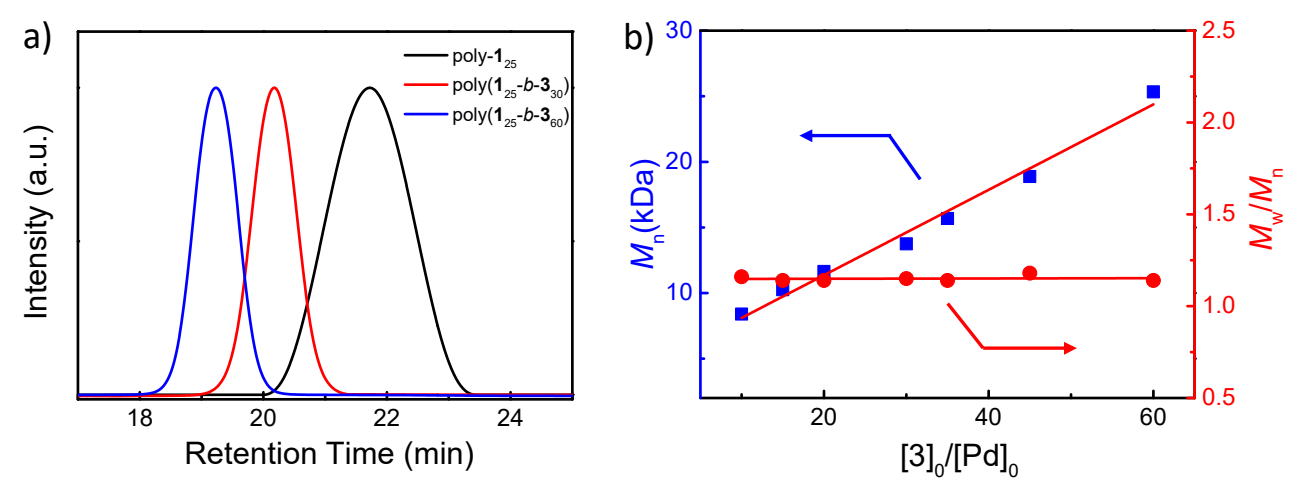

Figure 5. (a) SEC of poly-1 $\mathbf{1}_{25}$, poly $\left(\mathbf{1}_{25}-b-\mathbf{3}_{30}\right)$ and chain extended poly $\left(\mathbf{1}_{25}-b-\mathbf{3}_{60}\right)$ performed by copolymerization of $\mathbf{3}$ with $\mathrm{Pd}(\mathrm{II})$-terminated poly $\left(\mathbf{1}_{25}-b-\mathbf{3}_{30}\right)$ as the macroinitiator $\left([3]_{0} /[\mathrm{Pd}]_{0}=30\right)$. (b) Plots of the $M_{\mathrm{n}}$ and $M_{\mathrm{w}} / M_{\mathrm{n}}$ values of poly $\left(\mathbf{1}_{\mathrm{m}}-b-\mathbf{3}_{\mathrm{n}}\right) \mathrm{s}$ with the initial feed ratios of monomer 3 to Pd(II)-terminated poly- $\mathbf{1}_{25}\left(M_{\mathrm{n}}=6.38 \mathrm{kDa}, M_{\mathrm{w}} / M_{\mathrm{n}}=1.17\right)$. SEC conditions: temperature $=40^{\circ} \mathrm{C}$; eluent $=$ THF

To collect detailed structural information, the one-pot synthetic block copolymer poly $\left(\mathbf{1}_{\mathrm{m}}-b-\mathbf{3}_{\mathrm{n}}\right) \mathrm{s}$ was characterized by FT-IR and NMR measurements. The FT-IR spectra of the polymer are given in Figure S28. More detailed information about the isolated block copolymer poly $\left(\mathbf{1}_{25}-b-\mathbf{3}_{60}\right)$ was obtained from ${ }^{1} \mathrm{H}$ NMR spectroscopy, as shown in Figure 6c. 
a)

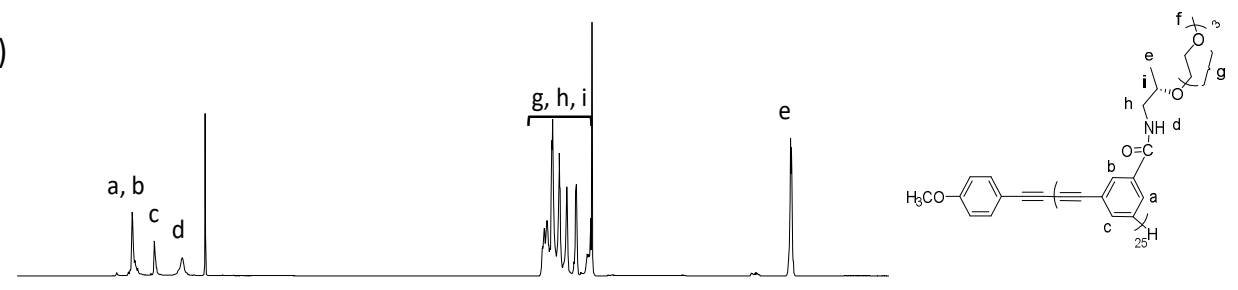

b)
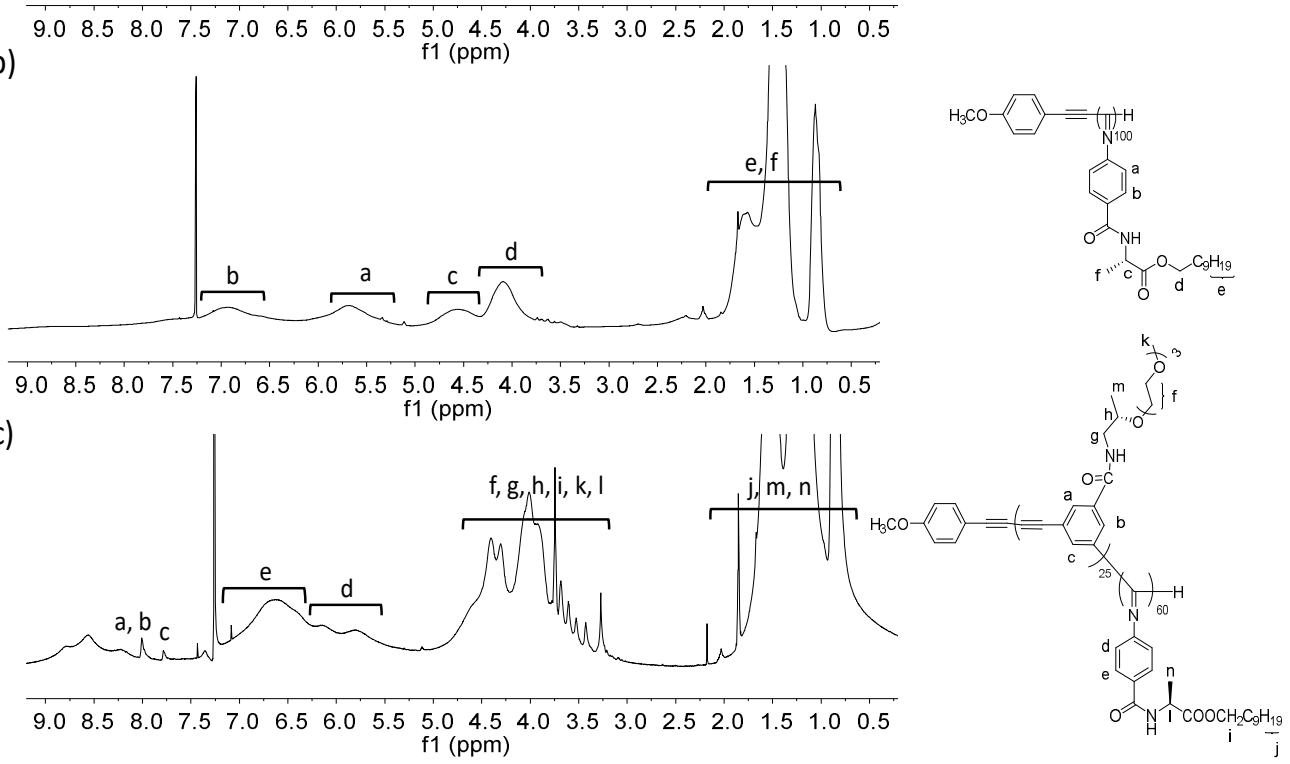

c)

Figure 6. ${ }^{1} \mathrm{H}$ NMR spectra $(600 \mathrm{MHz})$ of PPE homopolymer poly-1 $\mathbf{1}_{25}$. (a) PPI homopolymer poly-3 $\mathbf{3}_{100}$.

(b) PPE- $b$-PPI block copolymer poly $\left(\mathbf{1}_{25}-b-3_{60}\right)(\mathbf{c})$ measured in $\mathrm{CDCl}_{3}$ at $25^{\circ} \mathrm{C}$.

As shown in Figure 6, proton signals that can be attributed to both PPE and PPI blocks were observed, and were the proton signals of PPE and PPI homopolymers. Monomer $\mathbf{1}$ exhibited resonance signals at 8.17, 7.89, and $7.29 \mathrm{ppm}$ corresponding to the asymmetric aryl ring, and the signal at $3.30 \mathrm{ppm}$ is attributed to the characteristic signal of the $\mathrm{OCH}_{3}$ of the PPE segment (Figure S16, Supplementary Materials). The ${ }^{1} \mathrm{H}$ NMR spectra of the obtained poly- $\mathbf{1}_{25}$ were similar after $\mathbf{1}$ was polymerized by the $\operatorname{Pd}(\mathrm{II})$ initiator (Figure 6a). The spectra showed a singlet resonance at 8.01, 7.78, and $7.50 \mathrm{ppm}$ ascribed to the phenyl ring and a singlet resonance at $3.27 \mathrm{ppm}$ of $\mathrm{OCH}_{3}$. The poly $\left(\mathbf{1}_{25}-b-\mathbf{3}_{60}\right)$ copolymer showed resonances at 8.01,7.78, 7.50, and $3.27 \mathrm{ppm}$, corresponding to the aryl and $\mathrm{OCH}_{3}$ protons of the PPE segment, and also exhibited resonances at 6.68 and $5.81 \mathrm{ppm}$, which were assigned to the aryl protons of the PPI segment. Phenyl isocyanide monomers were consumed by SEC and participated in the copolymerization.

To obtain information on the chiroptical properties of the synthetic block copolymer, $\mathrm{CD}$ and UV-vis spectra were measured in THF at $25{ }^{\circ} \mathrm{C}(c=0.03 \mathrm{mg} / \mathrm{mL})$ (Figure 7). As shown in Figure 7 , poly $\left(\mathbf{1}_{25}-b-\mathbf{3}_{60}\right)$ and poly $\left(\mathbf{1}_{25}-b-\mathbf{4}_{60}\right)$ had the same absorption profiles, with the maximum located at $364 \mathrm{~nm}$. Poly $\left(\mathbf{1}_{25}-b-\mathbf{3}_{60}\right)$ and poly $\left(\mathbf{1}_{25}-b-\mathbf{4}_{60}\right)$ exhibited weak Cotton effects at $308 \mathrm{~nm}$, indicating that the content of poly- $\mathbf{1}_{25}$ was low after polymerization. Poly $\left(\mathbf{1}_{25}-b-\mathbf{3}_{60}\right)$ showed a negative Cotton effect at $364 \mathrm{~nm}$, whereas poly $\left(\mathbf{1}_{25}-b-\mathbf{4}_{60}\right)$ showed a positive Cotton effect at this absorption region. These results indicate that a helical conformation along the main chain with a preferred handedness of the polymers was formed, probably through the interaction of the polyisocyanide skeleton and chiral amide pedants. 


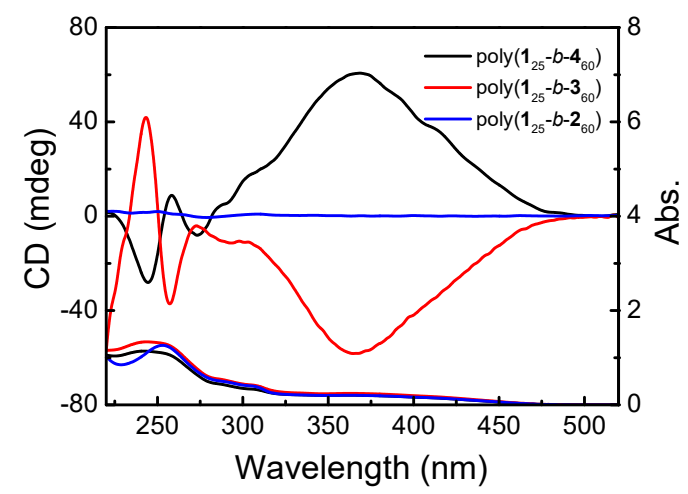

Figure 7. CD and UV-vis spectra of poly $\left(\mathbf{1}_{25}-b-\mathbf{2}_{60}\right)$, poly $\left(\mathbf{1}_{25}-b-\mathbf{3}_{60}\right)$, and poly $\left(\mathbf{1}_{25}-b-\mathbf{4}_{60}\right)$ measured in THF at $25{ }^{\circ} \mathrm{C}(\mathrm{c}=0.03 \mathrm{mg} / \mathrm{mL})$.

During the investigation, fluorescence emission was observed from the model compounds poly- $\mathbf{1}_{25}$ and poly $\left(\mathbf{1}_{25}-b-\mathbf{3}_{30}\right)$. As shown in Figure $8 \mathrm{a}$, when the concentration increased from 0.001 to $0.025 \mathrm{~g} / \mathrm{L}$, the emission intensity at $\lambda_{\mathrm{em}}=350 \mathrm{~nm}$ gradually increased. As shown in Figure $8 \mathrm{~b}$, the sample poly $\left(\mathbf{1}_{25}-b-\mathbf{3}_{30}\right)$ was strongly emissive in the fluorescence spectra at a concentration of $0.003 \mathrm{~g} / \mathrm{L}$ in THF. When the concentration increased from 0.003 to $0.06 \mathrm{~g} / \mathrm{L}$, the emission intensity at $\lambda_{\mathrm{em}}=304 \mathrm{~nm}$ gradually decreased. Unexpectedly, the emission intensity dropped to $5 \%$ of that the highest intensity $(0.003 \mathrm{~g} / \mathrm{L})$ as the concentration increased from 0.003 to $0.06 \mathrm{~g} / \mathrm{L}$. The polymer underwent aggregation-caused quenching (ACQ) effect in the aggregated state.
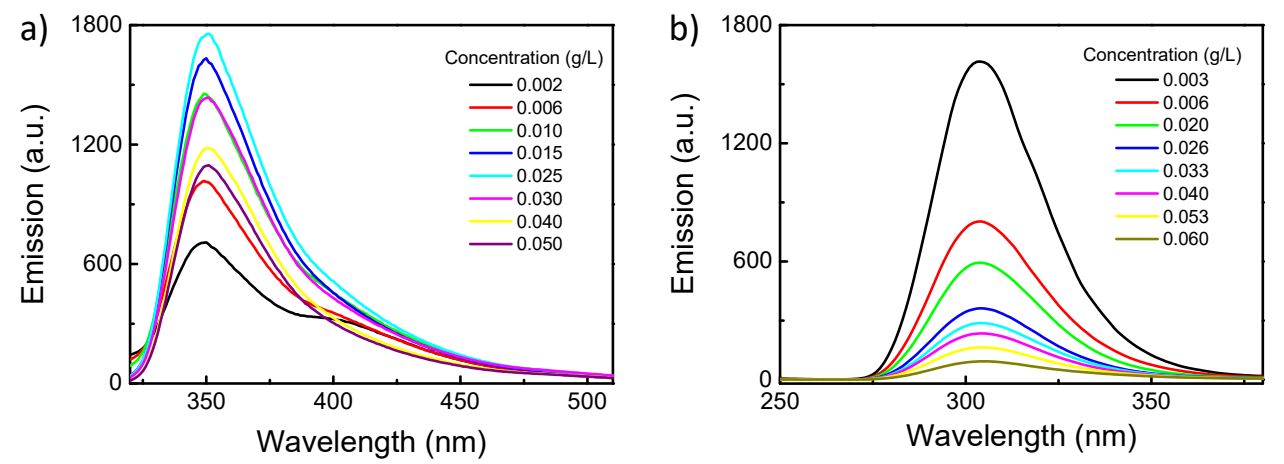

Figure 8. Emission spectra of poly-1 $\mathbf{1}_{25}$ (a) and poly $\left(\mathbf{1}_{25}-b-\mathbf{3}_{30}\right)(\mathbf{b})$ in THF at different concentrations measured at room temperature $(\lambda \operatorname{exc}(a)=300 \mathrm{~nm}, \lambda \operatorname{exc}(b)=210 \mathrm{~nm})$.

The fluorescence behavior of poly $\left(\mathbf{1}_{25}-b-\mathbf{3}_{30}\right)$ was systematically studied in THF/water mixtures with different water volume fractions $\left(f_{\mathrm{w}}\right)$ at a concentration of $0.03 \mathrm{~g} / \mathrm{L}$, based on the consideration that water is a poor solvent for these compounds and may induce molecular aggregation. The fluorescence spectra of poly $\left(\mathbf{1}_{25}-b-\mathbf{3}_{30}\right)$ are shown in Figure 9. In a pure THF solution, a weak emission peak was observed at $350 \mathrm{~nm}$. As the water fraction increased from $10 \%$ to $30 \%$, the emission gradually intensified. The strongest fluorescence intensity was observed at a $f_{w}$ of $30 \%$, with an intensity enhancement of approximately 5.6-fold compared to that of the pure THF solution. When the water content was greater than $30 \%$, the emission gradually decreased. 


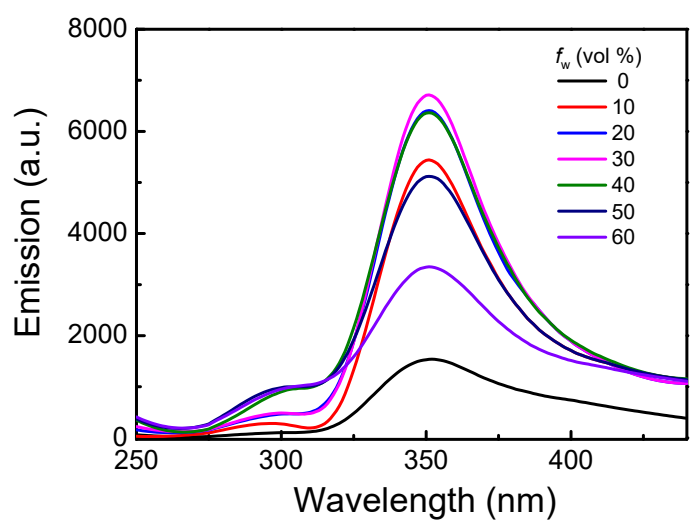

Figure 9. Emission spectra of poly $\left(\mathbf{1}_{25}-b-\mathbf{3}_{30}\right)$ in THF/water mixtures with different water fractions $\left(\mathrm{f}_{\mathrm{w}}\right)$ at the concentration of $0.03 \mathrm{~g} / \mathrm{L}(\lambda \operatorname{exc}=230 \mathrm{~nm})$.

To obtain the self-assembly structure, a polar protic solvent, $\mathrm{CH}_{3} \mathrm{OH}$, was added to the THF solution of the poly $\left(\mathbf{1}_{25}-b-\mathbf{3}_{30}\right)$ at room temperature. Figure 10 shows the CD and UV-vis spectra of poly $\left(\mathbf{1}_{25}-b-\mathbf{3}_{30}\right)$ in different $\mathrm{THF} / \mathrm{CH}_{3} \mathrm{OH}$ mixtures. Interestingly, the $\mathrm{CD}$ spectra of the copolymer showed distinct Cotton effects at $270 \mathrm{~nm}$ upon addition of $\mathrm{CH}_{3} \mathrm{OH}$. As shown in Figure 10, the copolymers showed a weak Cotton effect at $270 \mathrm{~nm}$ in THF. For $0-40 \% \mathrm{CH}_{3} \mathrm{OH}$ in THF, there was no change in the Cotton value of the copolymer at $270 \mathrm{~nm}$. For a $\mathrm{CH}_{3} \mathrm{OH}$ fraction of $50 \%$, the $\mathrm{CD}$ signal intensity at $270 \mathrm{~nm}$ showed some changes. By further increasing the $\mathrm{CH}_{3} \mathrm{OH}$ amount to $70 \%$, the $\mathrm{CD}$ signals at $270 \mathrm{~nm}$ increased. When the volume of $\mathrm{CH}_{3} \mathrm{OH}$ was equal to $80 \%$, the $\mathrm{CD}$ signals intensity at $270 \mathrm{~nm}$ dramatically increased. Thus, the Cotton effects of the poly $\left(\mathbf{1}_{25}-b-\mathbf{3}_{30}\right)$ at approximately $270 \mathrm{~nm}$ in THF/ $\mathrm{CH}_{3} \mathrm{OH}$ were assigned to the benzene ring skeleton. These results suggested that block copolymers may self-assemble into achiral aggregates.

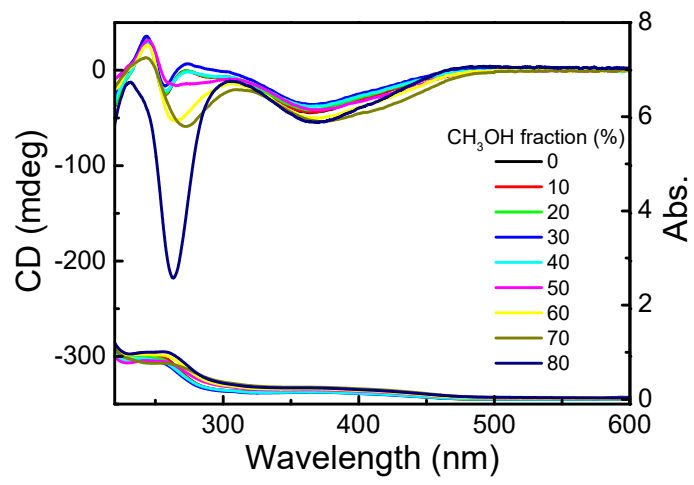

Figure 10. $\mathrm{CD}$ and UV-vis spectra of poly $\left(\mathbf{1}_{25}-b-\mathbf{3}_{30}\right)$ measured in $\mathrm{THF} / \mathrm{CH}_{3} \mathrm{OH}$ mixtures with different $\mathrm{CH}_{3} \mathrm{OH}$ fractions at the concentration of $0.03 \mathrm{~g} / \mathrm{L}$ at room temperature.

The self-assembly morphology of the aggregates was then investigated using atomic force microscopy (AFM) by spin-casting from the THF $/ \mathrm{CH}_{3} \mathrm{OH}(v: v=2: 8)$ solution of poly $\left(\mathbf{1}_{25}-b-\mathbf{3}_{30}\right)$ at room temperature $(\mathrm{c}=0.20 \mathrm{~g} / \mathrm{L})$. As shown in Figure 11a, well-defined spherical nanoparticles were clearly observed in the taping mode AFM image. The average diameter of the particles was estimated to be approximately $105 \mathrm{~nm}$. The self-assembled structures of poly $\left(\mathbf{1}_{25}-b-\mathbf{3}_{30}\right)$ in THF $/ \mathrm{CH}_{3} \mathrm{OH}$ solutions $(v: v=2: 8)$ were further studied by transmission electron microscopy (TEM). As shown in Figure 11b, the TEM image confirmed the formation of homogeneous nanoparticles, and the diameters were determined to be approximately $110 \mathrm{~nm}$. The poly $\left(\mathbf{1}_{25}-b-\mathbf{3}_{30}\right)$ was able to self-assemble into spherical nanostructures in the selective $\mathrm{THF} / \mathrm{CH}_{3} \mathrm{OH}$ solution. 

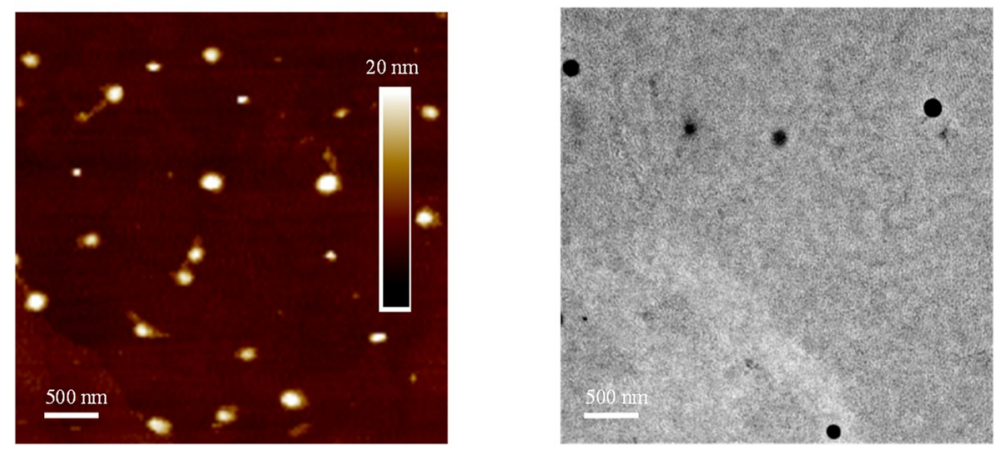

Figure 11. AFM height image (a) and TEM image (b) of the self-assembled structures of poly $\left(\mathbf{1}_{25}-b-\mathbf{3}_{30}\right)$ in $\mathrm{THF} / \mathrm{CH}_{3} \mathrm{OH}$ solutions (v:v = 2:8).

\section{Conclusions}

$m$-Phenylene ethynylene bearing an amide linkage pendant was synthesized and polymerized to form a novel predominantly one-handed helical structure $m$-PPE. Poly- $\mathbf{1}_{25}$ showed a positive CD signal at a wavelength of approximately $308 \mathrm{~nm}$ and a negative second Cotton effect at a wavelength of approximately $289 \mathrm{~nm}$ in acetonitrile, THF, 1,4-dioxane, and $\mathrm{H}_{2} \mathrm{O}$. Poly- $\mathbf{1}_{25}$ underwent a unique conformational change, such as a helix-helix transition of the polymer backbone, in mixed solvents without the assistance of extraneous molecules. The helical sense of poly-1 $\mathbf{1}_{25}$ was able to be controlled by changing the solvent composition. The polymer had a negative $C D$ signal at a wavelength of approximately $308 \mathrm{~nm}$ and a positive CD signal at a wavelength of approximately $289 \mathrm{~nm}$ in the THF $/ \mathrm{CHCl}_{3}$ mixed solvent, and the signs of these $\mathrm{CD}$ signals were opposite to those in pure THF at the same concentration, indicating that the polymer assumed helical conformations with reversed senses in the mixture solvents. We concluded that optically active poly ( $m$-phenylacetylenes) underwent a unique helix-helix transition as a response to a mixed solvent stimuli. Finally, amphiphilic poly(meta-phenylene ethynylene)-block-polyisocyanide block copolymers containing hydrophilic PPE and hydrophobic PPI segments were facilely prepared using a one-pot synthesis method. These block copolymers can self-assemble into well-defined spherical nanostructures in selective solvents. We believe that the present study will provide a facile one-pot synthetic methodology for the preparation of functional optically active (co)polymers, which can be used as semiconducting and chiral materials in the future.

Supplementary Materials: The following are available online at http:/ /www.mdpi.com/2073-4360/10/9/936/s1. Author Contributions: N.L. designed this work and C.L. conducted the experiments. X.X. and L.X. discussed and analyzed data. In addition, X.X. and L.X. reviewed the English manuscript.

Funding: This work is supported by the National Natural Scientific Foundation of China (21574036, 51673057, and 21622402).

Acknowledgments: The authors are thankful Zong-Quan Wu for our help.

Conflicts of Interest: The authors declare no conflict of interest

\section{References}

1. Shen, J.; Okamoto, Y. Efficient Separation of Enantiomers Using Stereoregular Chiral Polymers. Chem. Rev. 2016, 116, 1094-1138. [CrossRef] [PubMed]

2. Naito, Y.; Tang, Z.L.; Iida, H.; Miyabe, T.; Yashima, E. Enantioseparation on Helical Poly(phenylacetylene)s Bearing Cinchona Alkaloid Pendants as Chiral Stationary Phases for HPLC. Chem. Lett. 2012, 41, 809-811. [CrossRef]

3. Zhou, L.; Chu, B.-F.; Xu, X.-Y.; Xu, L.; Liu, N.; Wu, Z.-Q. Significant Improvement on Enantioselectivity and Diastereoselectivity of Organocatalyzed Asymmetric Aldol Reaction Using Helical Polyisocyanides Bearing Proline Pendants. ACS Macro Lett. 2017, 6, 824-829. [CrossRef] 
4. Ke, Y.-Z.; Nagata, Y.; Yamada, T.; Suginome, M. Majority-Rules Type Helical Poly(quinoxaline-2,3-diyl)s as Highly Efficient ChiralityAmplification Systems for Asymmetric Catalysis. Angew. Chem. Int. Ed. 2015, 54, 9333-9337. [CrossRef] [PubMed]

5. Tang, Z.L.; Iida, H.; Hu, H.Y.; Yashima, E. Remarkable Enhancement of the Enantioselectivity of an Organocatalyzed Asymmetric Henry Reaction Assisted by Helical Poly(phenylacetylene)s Bearing Cinchona Alkaloid Pendants via an Amide Linkage. ACS Macro Lett. 2012, 1, 261-265. [CrossRef]

6. Zhou, L.; Shen, L.; Huang, J.; Liu, N.; Zhu, Y.-Y.; Wu, Z.-Q. Optically Active Helical Polyisocyanides Bearing Chiral Phosphine Pendants: Facile Synthesis and Application in Enantioselective Rauhut-Currier Reaction. Chin. J. Polym. Sci. 2018, 36, 163-170. [CrossRef]

7. Maeda, K.; Yashima, E. Helical Polyacetylenes Induced via Noncovalent Chiral Interactions and Their Applications as Chiral Materials. Top. Curr. Chem. 2017, 375, 72. [CrossRef] [PubMed]

8. Fujiki, M. Supramolecular Chirality: Solvent Chirality Transfer in Molecular Chemistry and Polymer Chemistry. Symmetry 2014, 6, 677-703. [CrossRef]

9. Nelson, J.C.; Saven, J.G.; Moore, J.S.; Wolynes, P.G. Solvophobically driven folding of nonbiological oligomers. Science 1997, 277, 1793-1796. [CrossRef] [PubMed]

10. Lahiri, S.; Thompson, J.L.; Moore, J.S. Solvophobically Driven $\pi$-Stacking of Phenylene Ethynylene Macrocycles and Oligomers. J. Am. Chem. Soc. 2000, 122, 11315-11319. [CrossRef]

11. Stone, M.T.; Fox, J.M.; Moore, J.S. A helicene-containing foldamer displaying highly solvent-dependent CD spectra. Org. Lett. 2004, 6, 3317-3320. [CrossRef] [PubMed]

12. Stone, M.T.; Moore, J.S. A Water-Soluble m-Phenylene Ethynylene Foldamer. Org. Lett. 2004, 6, 469-472. [CrossRef] [PubMed]

13. Abe, H.; Murayama, D.; Kayamori, F.; Inouye, M. Saccharide-Linked Ethynylpyridine Oligomers: Primary Structures Encode Chiral Helices. Macromolecules 2008, 41, 6903-6909. [CrossRef]

14. Liu, R.; Shiotsuki, M.; Masuda, T.; Sanda, F. Synthesis and Chiroptical Properties of Hydroxyphenylglycine-Based Poly(m-phenyleneethynylene-p-phenyleneethynylene)s. Macromolecules 2009, 42, 6115-6122. [CrossRef]

15. Hill, D.J.; Mio, M.J.; Prince, R.B.; Hughes, T.S.; Moore, J.S. A Field Guide to Foldamers. Chem. Rev. 2001, 101, 3893-4012. [CrossRef] [PubMed]

16. Nakano, T.; Okamoto, Y. Synthetic Helical Polymers: Conformation and Function. Chem. Rev. 2001, 101, 4013-4038. [CrossRef] [PubMed]

17. Yashima, E.; Maeda, K.; Iida, H.; Furusho, Y.; Nagai, K. Helical Polymers: Synthesis, Structures, and Functions. Chem. Rev. 2009, 109, 6102-6211. [CrossRef] [PubMed]

18. Watanabe, J.; Okamoto, S.; Satoh, K.; Sakajiri, K.; Furuya, H.; Abe, A. Reversible Helix-helix Transition of Poly( $\beta$-phenylpropyll-aspartate) Involving a Screw-Sense Inversion in the Solid State. Macromolecules 1996, 29, 7084-7088. [CrossRef]

19. Fujiki, M. Diversity and Selection in Self-Assembled Tetrameric Capsule. J. Am. Chem. Soc. 2000, 122, 3336-3343. [CrossRef]

20. Tang, K.; Green, M.M.; Cheon, K.S.; Selinger, J.V.; Garetz, B.A. Chiral Conflict. The Effect of Temperature on the Helical Sense of a Polymer Controlled by the Competition between Structurally Different Enantiomers: From Dilute Solution to the Lyotropic Liquid Crystal State. J. Am. Chem. Soc. 2003, 125, 7313-7323. [CrossRef] [PubMed]

21. Maeda, K.; Okamoto, Y. Synthesis and Conformational Characteristics of Poly(phenyl isocyanate)s Bearing an Optically Active Ester Group. Macromolecules 1999, 32, 974-980. [CrossRef]

22. Pijper, D.; Feringa, B.L. Molecular Transmission: Controlling the Twist Sense of a Helical Polymer with a Single Light-Driven Molecular Motor. Angew. Chem. Int. Ed. 2007, 46, 3693-3696. [CrossRef] [PubMed]

23. Li, J.; Schuster, G.B.; Cheon, K.S.; Green, M.M.; Selinger, J.V. Switching a Helical Polymer between Mirror Images Using Circularly Polarized Light. J. Am. Chem. Soc. 2000, 122, 2603-2612. [CrossRef]

24. Otsuka, I.; Sakai, R.; Satoh, T.; Kakuchi, R.; Kaga, H.; Kakuchi, T. Metal-cation-induced chiroptical switching for poly(phenylacetylene) bearing a macromolecular ionophore as a graft chain. J. Polym. Sci. Part A Polym. Chem. 2005, 43, 5855-5863. [CrossRef]

25. Otsuka, I.; Sakai, R.; Kakuchi, R.; Satoh, T.; Kakuchi, T. Chiroptical switching system based on the host-guest interaction between metal cations and poly(phenylacetylene)s bearing polycarbohydrate ionophore. Eur. Polym. J. 2008, 44, 2971-2979. [CrossRef] 
26. Freire, F.; Seco, J.M.; Quinoa, E.; Riguera, R. Chiral Amplification and Helical-Sense Tuning by Mono- and Divalent Metals on Dynamic Helical Polymers. Angew. Chem. Int. Ed. 2011, 50, 11692-11696. [CrossRef] [PubMed]

27. Okamoto, Y.; Nakano, T.; Ono, E.; Hatada, K. Synthesis and Reversible Stereomutation of Optically Active Poly[(S)-diphenyl(1-methylpyrrolidin-2-yl)methyl methacrylate]. Chem. Lett. 1991, 20, 525-528. [CrossRef]

28. Sanda, F.; Terada, K.; Masuda, T. Synthesis, Chiroptical Properties, and pH Responsibility of Aspartic Acidand Glutamic Acid-Based Helical Polyacetylenes. Macromolecules 2005, 38, 8149-8154. [CrossRef]

29. Nakako, H.; Nomura, R.; Masuda, T. Helix Inversion of Poly(propiolic esters). Macromolecules 2001, 34, 1496-1502. [CrossRef]

30. Yamazaki, K.; Yokoyama, A.; Yokozawa, T. Solvent and Temperature Effect on Chiral Conformation of Poly( $m$-benzamide)s. Macromolecules 2006, 39, 2432-2434. [CrossRef]

31. Morino, K.; Maeda, K.; Yashima, E. Helix-Sense Inversion of Poly(phenylacetylene) Derivatives Bearing an Optically Active Substituent Induced by External Chiral and Achiral Stimuli. Macromolecules 2003, 36, 1480-1486. [CrossRef]

32. Freire, F.; Quiñoá, E.; Riguera, R. Supramolecular Assemblies from Poly(phenylacetylene)s. Chem. Rev. 2015, 116, 1242-1271. [CrossRef] [PubMed]

33. Kang, S.; Ono, R.J.; Bielawski, C.W. Controlled Catalyst Transfer Polycondensation and Surface-Initiated Polymerization of a p-Phenyleneethynylene-Based Monomer. J. Am. Chem. Soc. 2013, 135, 4984-4987. [CrossRef] [PubMed]

34. Cox, J.R.; Müller, P.; Swager, T.M. Interrupted Energy Transfer: Highly Selective Detection of Cyclic Ketones in the Vapor Phase. J. Am. Chem. Soc. 2011, 133, 12910-12913. [CrossRef] [PubMed]

35. Wang, Y.; Wilson, J.N.; Smith, M.D.; Bunz, U.H.F. TEMPO-Substituted PPEs: Polystyrene-PPE Graft Copolymers and Double Graft Copolymers. Macromolecules 2004, 37, 9701-9708. [CrossRef]

36. Lee, J.K.; Jung, Y.H.; Tok, J.B.-H.; Bao, Z.N. Syntheses of Organic Molecule-DNA Hybrid Structures. ACS Nano 2011, 5, 2067-2074. [CrossRef] [PubMed]

37. De, S.; Ramakrishnan, S. Folding of a Donor-Containing Ionene by Intercalation with an Acceptor. Chem. Asian J. 2011, 6, 149-156. [CrossRef] [PubMed]

38. Banno, M.; Yamaguchi, T.; Nagai, K.; Kaiser, C.; Hecht, S.; Yashima, E. Optically Active, Amphiphilic Poly(meta-phenylene ethynylene)s: Synthesis, Hydrogen-Bonding Enforced Helix Stability, and Direct AFM Observation of Their Helical Structures. J. Am. Chem. Soc. 2012, 134, 8718-8728. [CrossRef] [PubMed]

39. Xue, Y.-X.; Zhu, Y.-Y.; Gao, L.-M.; He, X.-Y.; Liu, N.; Zhang, W.-Y.; Yin, J.; Ding, Y.S.; Zhou, H.; $\mathrm{Wu}, \mathrm{Z}$.-Q. Air-Stable (Phenylbuta-1,3-diynyl)palladium(II) Complexes: Highly Active Initiators for Living Polymerization of Isocyanides. J. Am. Chem. Soc. 2014, 136, 4706-4713. [CrossRef] [PubMed]

40. Su, M.; Liu, N.; Wang, Q.; Wang, H.-Q.; Yin, J.; Wu, Z.-Q. Facile Synthesis of Poly(phenyleneethynylene)block-Polyisocyanide Copolymers via Two Mechanistically Distinct, Sequential Living Polymerizations Using a Single Catalyst. Macromolecules 2016, 49, 110-119. [CrossRef]

41. Xue, Y.-X.; Chen, J.-L.; Jiang, Z.-Q.; Yu, Z.; Liu, N.; Yin, J.; Zhu, Y.-Y.; Wu, Z.-Q. Living polymerization of arylisocyanide initiated by the phenylethynyl palladium (II) complex. Polym. Chem. 2014, 5, 6435-6438. [CrossRef]

42. Matsuda, K.; Stone, M.T.; Moore, J.S. Helical Pitch of $m$-Phenylene Ethynylene Foldamers by Double Spin Labeling. J. Am. Chem. Soc. 2002, 124, 11836-11837. [CrossRef] [PubMed]

43. Brunsveld, L.; Meijer, E.W.; Prince, R.B.; Moore, J.S. Self-Assembly of Folded $m$-Phenylene Ethynylene Oligomers into Helical Columns. J. Am. Chem. Soc. 2001, 123, 7978-7984. [CrossRef] [PubMed]

(C) 2018 by the authors. Licensee MDPI, Basel, Switzerland. This article is an open access article distributed under the terms and conditions of the Creative Commons Attribution (CC BY) license (http://creativecommons.org/licenses/by/4.0/). 